\title{
Spinal Textiloma (Gossypiboma): A Report of Three Cases Misdiagnosed as Tumour
}

\author{
Soner Şahin' ${ }^{1}$ Cem Atabey², Mehmet Şimşek ${ }^{3}$, Sait Naderi ${ }^{3}$ \\ ${ }^{1}$ Department of Neurosurgery, Kocaeli Derince Research and Teaching Hospital, Kocaeli, Turkey \\ ${ }^{2}$ Department of Neurosurgery, Gülhane Military Academy Haydarpaşa Training Hospital, Istanbul, Turkey \\ ${ }^{3}$ Department of Neurosurgery, Ümraniye Research and Teaching Hospital, Istanbul, Turkey
}

\section{ABSTRACT}

Background: Textile products commonly used in surgery (e.g., sponges or gauze) have been known to cause complications after spinal surgery. Associated complications usually arise months or even years after the primary surgery. In case of spine surgery, these bodies are often detected during neuroradiological evaluations to investigate reported back pain; however, this complication often remains asymptomatic.

Aims: The research is intended to increase awareness among both spinal surgeons and neuroradiologists of this potential complication.

Study Design: Retrospective study.

Methods: This study is a retrospective case series of three patients with retained surgical textile products who had been misdiagnosed with spinal tumour. The medical records of the patients were reviewed and demographic data, clinical aspects, initial diagnosis, surgical procedures, time interval between previous operation and onset of symptoms, laboratory findings, radiological findings, treatment, and outcome were analysed.

Results: The three patients included two women and one man aged between 64 and 67 years. All patients had a previous surgery for lumbar disc herniation. The time from the previous surgical procedures to presentation ranged from 3 to 17 years. All patients presented with non-specific lower back pain and/or radiculopathy without clinical findings of infection. Laboratory parameters were otherwise normal. All three cases had been misdiagnosed as a spinal tumor based on magnetic resonance imaging findings. During new surgical procedures, gauze bandages, i.e., surgical textiles left during a previous operation, were found.

Conclusion: Textiloma is an important and rarely mentioned potential neurosurgical complication that may remain asymptomatic for years. They are more common in obese patients, after emergency surgery, and with unplanned changes in surgical procedure such as bleeding and unintended neurosurgical complications. Neuroradiological findings are variable and non-specific; thus, patients could be misdiagnosed with a spinal tumor or abscess. Likewise, in patients with a history of spinal surgery, spinal abscesses, haematomas, hypertrophic scars, fibrosarcomas, rhabdomyosarcomas, and schwannomas should definitely be considered in the differential diagnosis and considered when planning diagnostic procedures. Appropriate antibiotic therapy is recommended when a suppurative complication is present or suspected. Textiloma is a medico-legal complication that can be prevented by the education of surgical staff, the counting method (preoperatively, at closure, and at the end), and use of products with radiopaque barcodes.

Key Words: Gauze bandage, spinal tumour, surgical textile products, lumbar spine, gossypiboma, foreign body granuloma

\section{Introduction}

Textile products commonly used in surgery (e.g., sponges or gauze) have been known to cause complications after spinal surgery. This complication has been called retained surgical sponge, textiloma, gossypiboma, and gauzoma in the literature. Although this complication has been well described due to professional and legal concerns, it has infrequently been reported and remains rare. The rate of textiloma was $0.7 \%$ in 10,000 lumbar disc operations (1-3). Although some foreign bodies remain clinically inactive, many are the causes of infection and abscesses in the early postoperative stages (4-7). In some cases, an inflammatory reaction may develop in peripheral tissues as well. This type of inflammation may develop to critical levels in the following months and years and cause massive lesions $(4,8-11)$.
In rare instances, textilomas can clinically and/or radiologically mimic spinal tumours. This study was designed to increase awareness among spinal surgeons and neuroradiologists of this complication. The cases of three patients referred to our clinic based on suspected spinal tumours are presented herein and discussed in light of the literature.

\section{Material and Methods}

This study was a retrospective case series of three patients with retained surgical textile products who underwent posterior lumbar spinal surgery in our neurosurgical department between January 2007 and December 2010. The medical records of the patients were reviewed and demographic data, clinical aspects, initial diagnosis, surgical procedures, time interval between previous operation and onset of symptoms, 

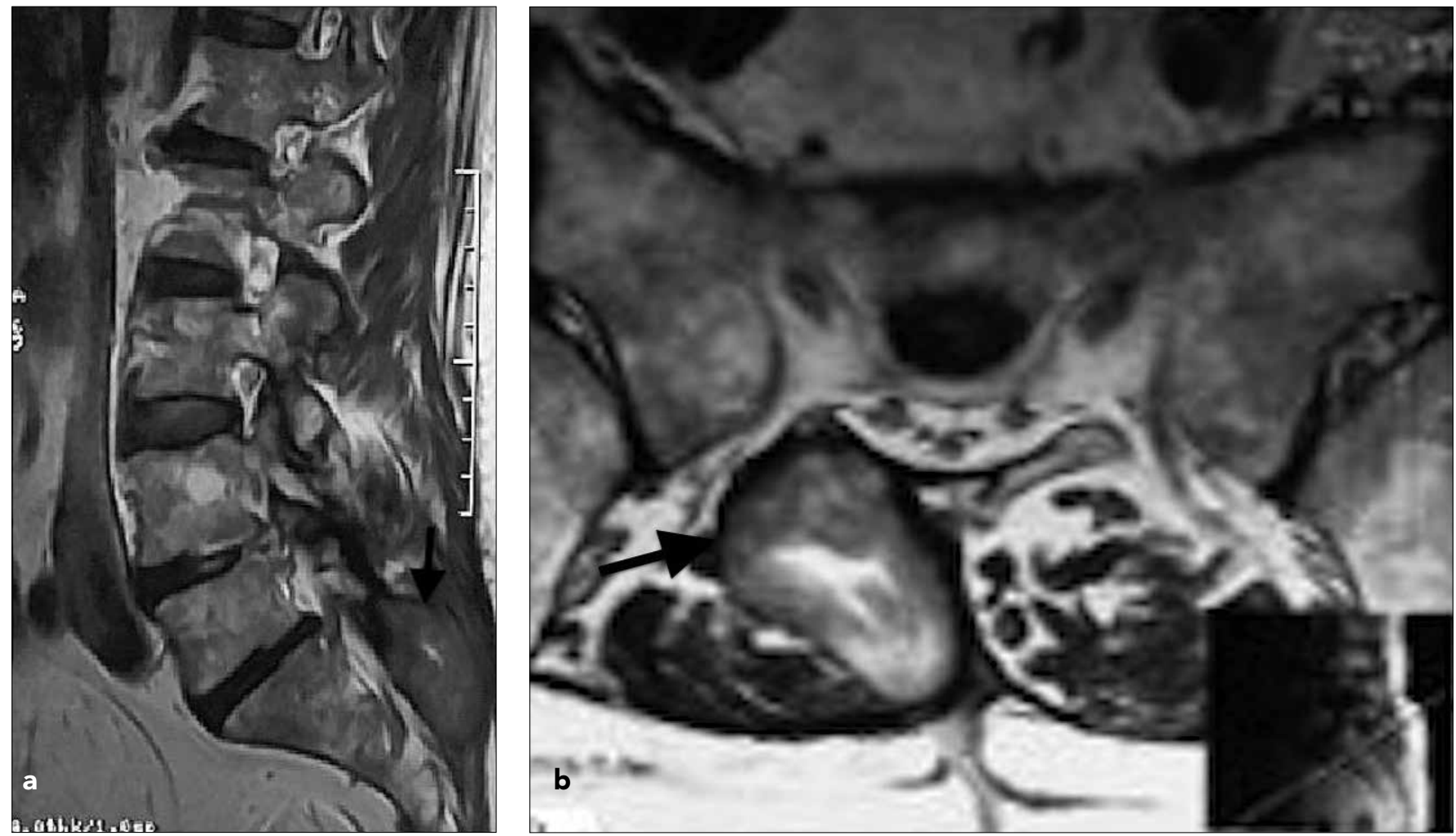

Figure 1. a, b. Preoperative sagittal (a) and axial (b) magnetic resonance imaging show a laminectomy defect at the L5 level on the right and a heterogeneous, $3 \times 6.5 \mathrm{~cm}$ mass located in the previously operated right paravertebral area, i.e., at the S1-S2 level
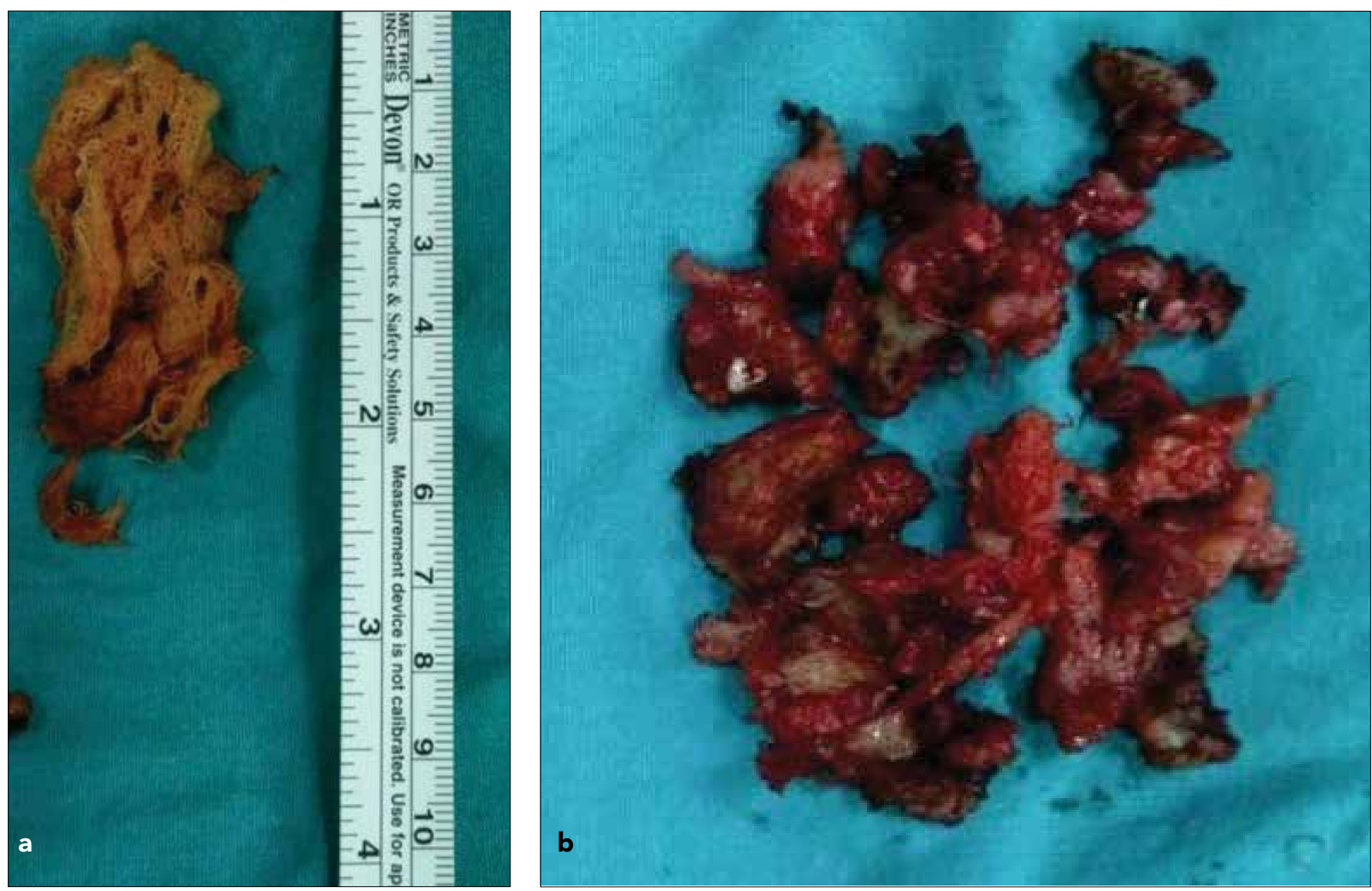

Figure 2. a, b. Intraoperative photos show a gauze bandage (a) and fibrotic tissues around the surgical site (b) 
laboratory findings, radiological findings, treatment, and outcome were analysed.

\section{Results}

The three patients included two women and one man aged between 64 and 67 years. All patients had a history of lumbar disc herniation. The time from the previous surgical procedures to presentation ranged from 3 to 17 years. All patients presented with non-specific lower back pain and/or radiculopathy without clinical findings of infection. Laboratory parameters were otherwise normal. None of the patients had a positive culture result. All patients were evaluated with magnetic resonance imaging (MRI). During new surgical procedures, gauze bandages, i.e., surgical textiles left during a previous operation, were found. Textilomas were removed surgically in all patients with a good outcome. Pathological examinations of biopsies of the area revealed no evidence of neoplasms.

\section{Case 1}

A 64-year-old male underwent an operation in 2007 due to a L5-S1 disc herniation and was admitted to our department due to lower back and right groin pain that had lasted for 2 months. A physical examination revealed a palpable irritation and trigger point at the S1-S2 localisation on the right side. A neurological examination revealed normal functioning. Laboratory tests were also normal. MRI showed a laminectomy defect at the $L 5$ level on the right and a $3 \times 6.5 \mathrm{~cm}$ hard mass lesion located at the S1-S2 level on the right, i.e., just under the paravertebral fascia (Figures $1 \mathrm{a}$ and $1 \mathrm{~b}$ ). A retained surgical sponge bandage was excised in a subsequent operation (Figures $2 \mathrm{a}$ and $2 \mathrm{~b}$ ). The postoperative MRI was otherwise normal. A histopathological examination of the excised tissue samples showed chronic inflammation but no evidence of neoplasm. No cell reproduction was observed when tissue samples were planted in culture media. The patient was symptom-free after surgery.

\section{Case 2}

A 64-year-old female underwent an operation 19 years ago to correct right L3-4, L4-5, and L5-S1 disc herniations. Her lower back pain persisted for a while after the operation and then subsided. She was admitted to our institution due to reported lower back and hip pain over the last 2 years. A neurological examination revealed a sequela of right foot drop. The laboratory test results were normal except for a high erythrocyte sedimentation rate (i.e., $49 \mathrm{~mm} / \mathrm{hour}$ ). A physical examination revealed a palpable irritation and trigger point at the S1 location on the right. A lumbosacral MRI showed laminectomy defects at the L3, L4, and L5 levels. An MRI also showed a space-occupying massive lesion in the posterior sacral area at the $\mathrm{S} 1$ level on the right (Figures $3 \mathrm{a}$ and $3 \mathrm{~b}$ ). During a subsequent surgical procedure, a gauze bandage $(3 \times 3.5 \mathrm{~cm}$ in size) and peripheral granulated tissue surrounding the mass were excised. The postoperative MRI was otherwise normal. Histopathological examination of the excised tissue samples confirmed the presence of a foreign body and


Figure 3. a, b. Sagittal (a) and axial (b) lumbosacral magnetic resonance imaging show a laminectomy defect at the L3, L4, and L5 levels and a hypointense, space-occupying, massive lesion in the posterior sacral area at the S1 level in the right paraspinal area 
chronic inflammation in both the gauze bandage and in the samples of peripheral tissues. No cell reproduction occurred when the tissue samples were planted in culture media. The patient was symptom-free after surgery.

\section{Case 3}

A 67-year-old female was admitted to our institution due to left leg and lumbar pain that had persisted for 9 months. The patient had undergone lumbar discectomy 5 years ago. She reported a persistent lower back pain postoperatively, and a left leg pain had recently developed. She was neurologically intact. An MRI showed a mass located in the paravertebral area at the L5-S1 level on the left (Figure 4). A gauze bandage was excised in a subsequent operation. The patient's complaints of pain decreased during the postoperative period. Histopathological examination revealed no tumoural lesions.

\section{Discussion}

Although estimates of the incidence of textilomas are difficult to make due to the low and slow rate of complication reports in the literature, textilomas are more common than expected in daily practice. Of all the textilomas reported in the USA, $1.5 \%$ occurred with operations in the spinal area. The rate of textilomas has been reported as $0.7 \%$ in 10,000 lumbar disc operations $(1-3,12)$. Fewer than 50 cases were reported in the period from 1965 to 2010, and most of these reports came from surgeons and radiologists who were not responsible for the condition $(2,13-15)$ (Table 1$)$. The three consecutive cases of patients referred to our centre with prediagnosis of spinal tumours were evaluated in light of the information found in the literature.

Another interesting aspect of one of our cases (i.e., Case 2 ) is the long time period between the primary surgery and the manifestation of clinical symptoms. A literature review revealed a case of spinal textiloma with the longest interval between surgery and clinical symptom manifestation and late diagnosis of 40 years $(8,14)$. Case 2 as presented in this report was diagnosed after 19 years, one of the most delayed cases reported in the literature. As we have learned from our cases so far, textilomas may remain asymptomatic for many years. Thus, they remain undiagnosed and cannot be removed surgically. Patients apply to a medical centre only when they have symptoms, and medico-legal problems of pathological diagnosis arise when a space-occupying lesion is detected neuroradiologically.

Textile products such as gauze bandages and cotton pads are widely used during surgical procedures for haemostasis, retraction, and dissection. In relation to the recent increase in complex spine surgeries, the number of gauze bandages and pads that are used in such surgeries has also increased $(9,10$, 12-18). Among these textile products, surgical sponges are the most commonly used.

Their frequent use, small size, and similar appearance to paravertebral muscle tissue after they have absorbed blood, particularly in large haemorrhagic surgical areas, contribute to the fact that they are sometimes overlooked. The literature reports cases of surgical textilomas that were diagnosed after
Table 1. Summary of textilomas in the paraspinal region after posterior spinal surgery in spinal literature

\begin{tabular}{|c|c|c|}
\hline Authors & $\begin{array}{l}\text { Number } \\
\text { of Cases }\end{array}$ & Previous Surgery \\
\hline \multirow[t]{3}{*}{ Akhaddar A et al. } & 6 & 4 Lumbar disc surgery \\
\hline & & $\begin{array}{l}1 \text { Lumbar spinal stenosis } \\
\text { (laminectomy) }\end{array}$ \\
\hline & & $\begin{array}{l}1 \text { Spondylolisthesis } \\
\text { (instrumentation) }\end{array}$ \\
\hline Naama O et al. & 1 & Lumbar disc surgery \\
\hline \multirow[t]{2}{*}{ Hakan T et al. } & 2 & 1 Lumbar disc surgery \\
\hline & & $\begin{array}{l}1 \text { L4-5 extraforaminal } \\
\text { schwannoma }\end{array}$ \\
\hline Chater-Cure G et al. & 1 & 1 Lumbar disc surgery \\
\hline \multirow[t]{2}{*}{ Atabey C et al. } & 8 & $\begin{array}{l}7 \text { Lumbar disc surgery + } \\
\text { Lumbar spinal stenosis } \\
\text { (laminectomy) }^{\star}\end{array}$ \\
\hline & & $\begin{array}{l}1 \text { Lumbar spinal stenosis } \\
\text { (laminectomy) }\end{array}$ \\
\hline Aydogan $\mathrm{M}$ et al. & 1 & 1 Lumbar disc surgery \\
\hline Okten Al et al. & 1 & 1 Lumbar disc surgery \\
\hline De winter et al. & 1 & 1 Lumbar disc surgery \\
\hline Kucukyuruk B et al. & 1 & 1 Lumbar disc surgery \\
\hline Turgut $M$ et al. & 1 & 1 Lumbar disc surgery* \\
\hline $\begin{array}{l}\text { Erdem G et al. } \\
\text { (laminectomy) }\end{array}$ & 1 & 1 Lumbar spinal stenosis \\
\hline Gifford RR et al. & 1 & $\begin{array}{l}1 \text { Lumbar spinal stenosis } \\
\text { (laminectomy) }\end{array}$ \\
\hline Vahdati SS et al. & 1 & 1 Lumbar disc surgery \\
\hline Abononu et al. & 1 & 1 Lumbar disc surgery \\
\hline \multirow[t]{2}{*}{ Sahin et al. } & 3 & 2 Lumbar disc surgery \\
\hline & & $\begin{array}{l}1 \text { Lumbar spinal stenosis } \\
\text { (laminectomy) }\end{array}$ \\
\hline
\end{tabular}

*The case was previously reported (Turgut $\mathrm{M}$ et al. Case number 7$)(9,10)$

13 days to 40 years $(14,15)$. Our cases were diagnosed after 3 , 19 , and 5 years had passed since the initial operation. Such delayed diagnosis can be attributed to the lack of awareness and the asymptomatic progression associated with this complication. Indeed, during emergency surgical interventions, particularly on obese patients and in elective surgery procedures, the textile products used may be overlooked, especially within a severely haemorrhagic surgical site. In our study, Case 2 had undergone spinal surgery at three levels, i.e., over a large surgical area, which may have contributed to the surgeon overlooking the sponge. Moreover, the asymptomatic nature of non-absorbable materials left in the surgical site is due to the inert quality of the cotton used to make such materials. Thus, no exudation or biochemical reaction is observed (12).

Foreign bodies that are left in the body due to negligence can manifest two major clinical patterns, i.e., infection or a tex- 


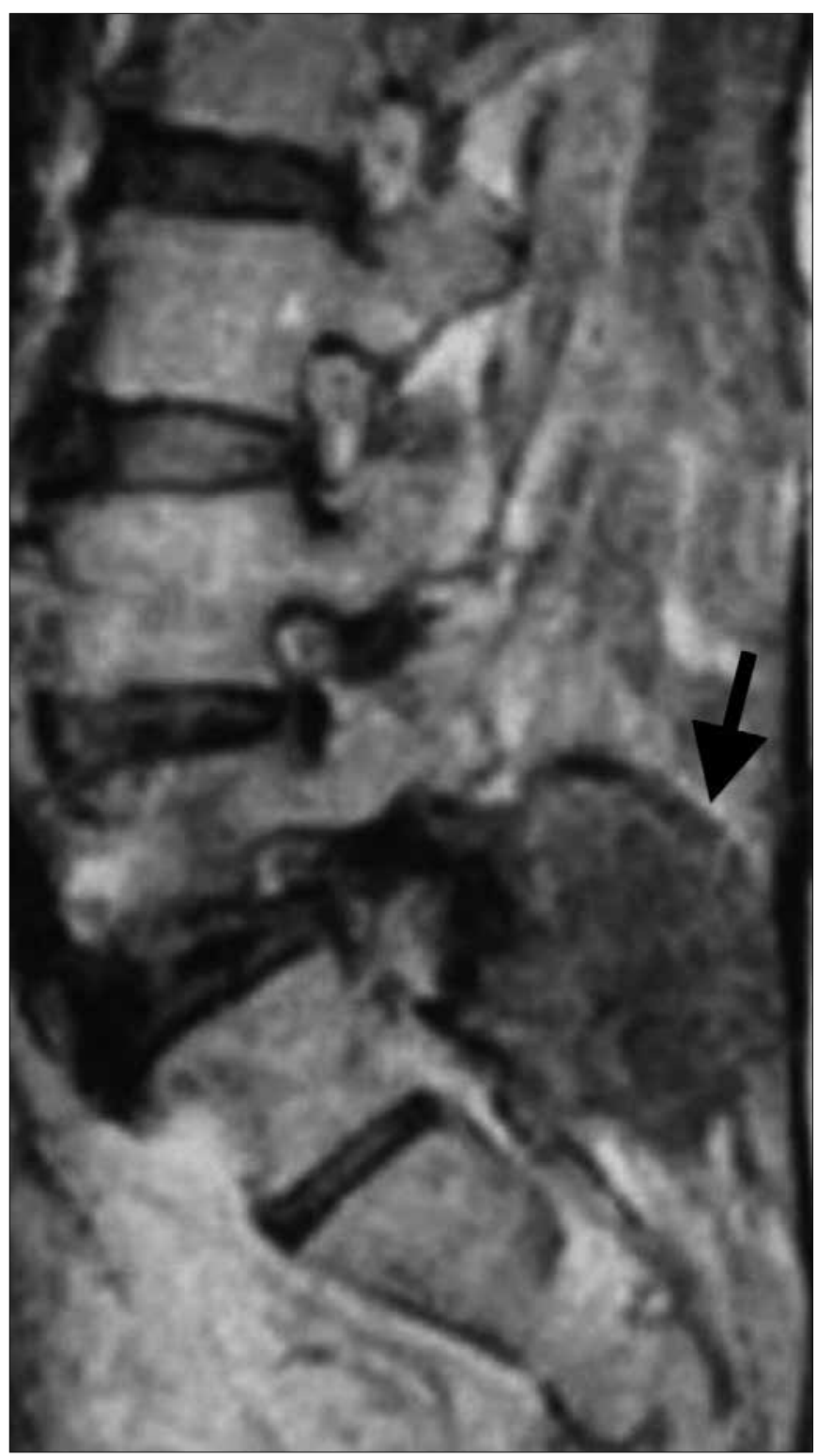

Figure 4. Sagittal lumbosacral magnetic resonance imaging shows a hypointense mass located in the left paravertebral area at the L5-S1 level

tiloma containing atypical cells. While infection is more common and occurs in early postoperative stages, textilomas are rare and occur in late postoperative stages (4-7). The mechanism for infection at the surgical site is based on the fact that the retained sponge acts as an incubation plate and leads to a superinfection, which in turn results in fistulisation. Septic collection in exudative forms and abscesses has been attributed to early superinfections $(2,12,15)$. All of our cases were diagnosed late, and none presented with exudative reactions.

Clearly, since foreign bodies that are left in the patient generally cause infections in the early post-surgical period, they should especially be considered for infections that do not respond to antibiotic therapy and recur. In such cases, laboratory tests cannot be used to pinpoint the cause of the infection, and advanced radiological examinations should be conducted to determine if a foreign body is the cause of infection. Although in the exudative form, acute phase reactants such as C-reactive protein, sedimentation, and leukocytosis are observed, laboratory tests may reveal normal results in the aseptic fibrinous form of textilomas. In patients with infections, often no growth is observed in the wound culture, which is usually associated with Staphylococcus strains $(2,9$, 14). In the medical history of all cases that were referred to our clinic, there were no clinical and laboratory signs of infection in the primary centre where they had their first surgical interventions, so no microbiological tests were performed. In addition, no microbiological pathogens were isolated in our operations. These cases may also be considered aseptic.

In the second pattern, i.e., the so-called aseptic fibrinous form, foreign bodies remain clinically inactive or cause tissue inflammation and reaction without abscess development. Foreign bodies and peripheral inflammation may grow significantly and thus reveal new clinical evidence through mass development $(2,12,15)$. The three cases presented herein were of this second form. No findings were found in the laboratory or histopathological evaluations to suggest the presence of the exudative form.

Historically, the radiological detection of foreign bodies was very difficult in the pre-MRI period and was accomplished by computer tomography (CT) and/or ultrasonography (USG). However, the retained textile product could be misdiagnosed as a paravertebral haematoma depending on the amount of blood absorbed into the tissue (10). Ultimately, the clinical importance of CT and USG has declined in the MRI era. The publication of MRI images of foreign bodies left in the pelvic, retroperitoneum, neck, chest, and paraspinal areas has facilitated the diagnosis of foreign bodies. De winter et al. (16) have suggested that high F-18 fluorodeoxyglucose (FDG) uptake in a missing foreign textile product within surgical sites may be a useful diagnostic method in modern nuclear medicine.

The aseptic fibrinous tissue reaction of textilomas is accompanied by adhesions and encapsulation, whereas the exudative tissue reaction is related to abscess formation and possible secondary bacterial infection. Both of these reaction types are observed differently via MRI $(4,6,7)$.These different MRI signal patterns depend on the amount of fluid and protein compounds retained in the textile product. Granulomas appear hypointense on T1-weighted and hyperintense on T2-weighted MRI images. If the lesion has capsule formation, it appears hypointense on both T1- and T2-weighted images (17-21). Textilomas may show an enhanced hyperintense rim around the hypointense centre after contrast medium administration. Kuwashima et al. have published MRI findings of two textiloma cases. The authors concluded that the surgical textile products contained serosanguineous fluid and high protein concentrations $(8,15,22-27)$. MRI showed the laminectomy defect at L5 (Case 1 and Case 3) and at L3-4-5 (Case 2) and a mass lesion in the posterior paraspinal region at these levels. The mass of each patient appeared hypointense on T1-weighted images and hyperintense on T2-weighted images (Case 1, Figures 1a and $1 \mathrm{~b}$ ). Diffusion-weighted MRI evaluations provide important information on the differentiation of mass lesions and ab- 
scesses (13). In the evaluation of our cases, no diffusion studies were conducted since no exudative forms were observed and no clinical or laboratory findings suggested the presence of an abscess. However, in cases that are suspected to involve a suppurative process, diffusion MRI should definitely be conducted. Likewise, patients with a history of spinal surgery, spinal abscesses, haematomas, hypertrophic scars, fibrosarcomas, rhabdomyosarcomas, and schwannomas should definitely be considered in the differential diagnosis and considered when planning diagnostic procedures (28-35) (Table 2). In our cases, a history of previous operations and long-lasting symptoms made us consider foreign bodies left in the surgical site. However, long post-operation intervals and the distant location of the 'masses' from the site of the initial procedure in the radiological examinations suggested extradural tumours.

Treatment for the clinical symptoms associated with textilomas involves surgical removal of the mass. Although some authors believe that the therapeutic approach must balance the potential risk of evolution of the foreign body and the risk associated with the surgical procedure if the textiloma remains asymptomatic, we recommend surgical removal of the textiloma because of health concerns and medico-legal aspects (3). Appropriate antibiotic therapy is recommended when a suppurative complication is present or suspected.

Whether a textiloma should be treated surgically or not is controversial. The complicated part of the issue is the medico-legal aspect. In our cases, there were signs of spaceoccupying tumoural lesion in the MRI reports so there was a necessity of diagnosis, and this was the important thing. Therefore, our cases were operated again due to the fact that the patients were symptomatic and there was a necessity of histopathological diagnosis.

The following suggestions should be followed in order to avoid leaving surgical textile products in a patient and the related complications:

1) All the textile products used should be counted at least three times (i.e., twice preoperatively and at the end of the operation).

2) Particularly in spinal surgeries with large operative sites, the use of small textile products should be avoided. However, if used, they should be fixed with radiopaque sutures.

3) Just before closure of the incisions, all textile products should be kept away from the surgical site.

4) Medical personnel should ensure that threaded cotton pads contain the ends.

5) All the products should contain a radiopaque marker that can be visualised under fluoroscopy.

6) Careful filling of surgical safety forms.

Regardless of these precautions, the surgical team should examine the surgical site in detail and evaluate the entire area with intraoperative fluoroscopy and by radiological methods if such an incident is suspected. Closure should not occur before these procedures are conducted. When medical records of our patients were investigated, no surgical safety forms were encountered and there were no numeric records of surgical textile products.
Table 2. Differential diagnosis of spinal textilomas

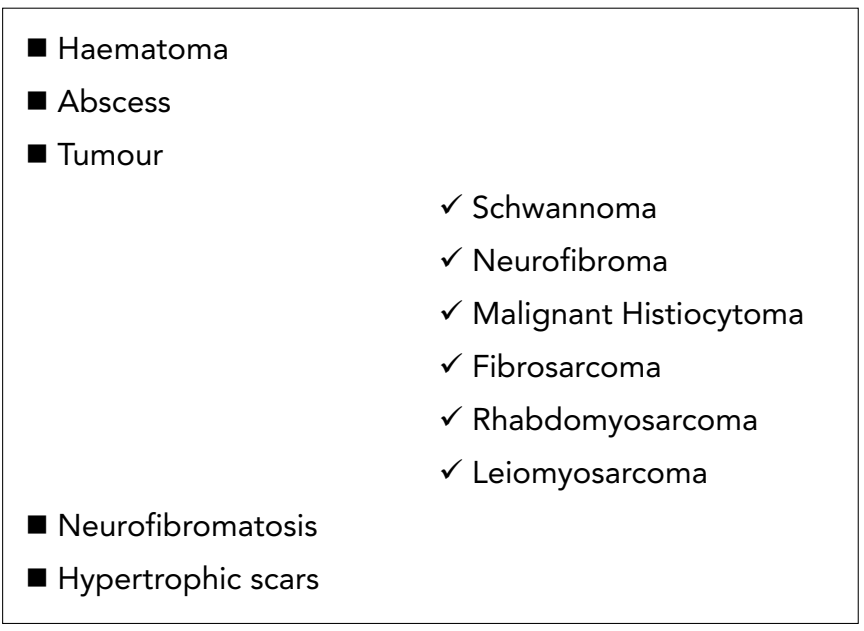

The counting of surgical textile products by auxiliary healthcare personnel still remains a serious source of error. Of the cases of foreign body retention within a surgical site, $88 \%$ are associated with errors in the direct counting procedures (13). Hence, only counting the products used is not the most efficient approach to avoid this particular complication. Use of products with a barcode, a data matrix code embedded in the textile products, or radiofrequency identification methods are more beneficial. Human error is natural and can never be totally eliminated. Accordingly, the intra-occupational training of healthcare personnel should be emphasised, and the aid of technology should be used to minimise the risk of textilomas.

In conclusion, the differential diagnosis of a textiloma should be considered for patients with surgical wound infections with no non-specific back pain and/or fever and neurological symptoms, and for patients with a history of spine surgery and suspected spinal tumours. The results of laboratory tests (i.e., sedimentation, C-reactive protein, and total blood count) may vary depending on the exudative or aseptic progression of the textiloma. MRI is the gold standard for diagnosis of textilomas. In preoperative diagnosis, to rule out spinal tumour lesions, the patient's history and radiological confirmation are quite important.

Ethics Committee Approval: N/A

Informed Consent: Written informed consent was obtained from patients.

Peer-review: Externally peer-reviewed.

Author contributions: Concept - S.S., S.N.; Design - S.S., S.N.; Supervision - S.S., S.N.; Resource - S.S., C.A., M.S.; Materials - S.S., M.S., S.N.; Data Collection \&/or Processing - S.S., M.S., S.N.; Analysis \&/or Interpretation - S.S., C.A., S.N.; Literature Search - S.S., C.A.; Writing - S.S., S.N.; Critical Reviews - S.S., C.A., S.N.

Conflict of Interest: The authors declared no conflict of interest

Financial Disclosure: The authors declared that this study received no financial support.

\section{References}

1. Ramirez LF, Thisted R. Complications and demographic characteristics of patients undergoing lumbar discectomy in community hospitals. Neurosurgery 1989;25:226-30. [CrossRef] 
2. Okten Al, Adam M, Gezercan Y. Textiloma: A case of foreign body mimicking a spinal mass. Eur Spine J 2006;15 Suppl 5:626-9. [CrossRef]

3. Karcnik TJ, Nazarian LN, Rao VM, Gibbons GE. Foreign body granuloma simulating solid neoplasm on MR. Clin Imaging 1997;21:269-72. [CrossRef]

4. Ford LT. Complications of lumbar-disc surgery, prevention, and treatment. Local complications. J Bone Joint Surg Am 1968;50:418-28.

5. Is M, Karatas A, Akgul M, Yildirim U, Gezen F. A retained surgical sponge (gossypiboma) mimicking a paraspinal abscess. $\mathrm{Br} \mathrm{J}$ Neurosurg 2007;21:307-8. [CrossRef]

6. Massie JB, Heller JG, Abitbol JJ, McPherson D, Garfin SR. Postoperative posterior spinal wound infections. Clin Orthop Relat Res 1992;284:99-108.

7. Yamagami T, Matsui $H$, Tsuji $H$, Ichimura $K$, Sano A. Effects of laminectomy and retained extradural foreign body on cauda equina adhesion. Spine (Phila Pa 1976) 1993;18:1774-81. [CrossRef]

8. Stoll A. Retained surgical sponge 40 years after laminectomy. Case report. Surg Neurol 1988;30:235-6. [CrossRef]

9. Turgut M, Akyuz O, Ozsunar Y, Kacar F. Sponge-induced granuloma ("gauzoma") as a complication of posterior lumbar surgery. Neurol Med Chir (Tokyo) 2005;45:209-11. [CrossRef]

10. Atabey C, Turgut M, llica AT. Retained surgical sponge in differential diagnosis of paraspinal soft-tissue mass after posterior spinal surgery: report of eight cases. Neurol India 2009;57:320-3. [CrossRef]

11. Kucukyuruk B, Biceroglu $H$, Abuzayed B, Ulu MO, Kafadar AM. Paraspinal gossybipoma: A case report and review of the literature. J Neurosci Rural Pract 2010;1:102-4. [CrossRef]

12. Marquardt G, Rettig J, Lang J, Seifert V. Retained surgical sponges, a denied neurosurgical reality? Cautionary note. Neurosurg Rev 2001;24:41-3. [CrossRef]

13. Akhaddar A. Boulahround O, Naama O, Al-boizidi A, Boucetta M. Paraspinal texiloma after Posterior Lumbar Surgery:A Wolf in sheep's Clothing World Neurosurgery 2012;2:375-80

14. Rajkovic Z, Altarac S, Papes D. An unusual cause of chronic lumbar back pain:Retained surgical gauze discovered after 40 years. Pain Med 2010;11:1777-9. [CrossRef]

15. Erdem G, Ates O, Kocak A, Alkan A. Lumbar gossypiboma. Diagn Interv Radiol 2010;16:10-2.

16. De Winter F, Huysse W, De Paepe P, Lambert B, Poffyn B, Dierckx R. High F-18 FDG uptake in a paraspinal textiloma. Clin Nucl Med 2002;27:132-3. [CrossRef]

17. Kim HS, Chung TS, Suh SH, Kim SY. MR imaging findings of paravertebral gossypiboma. AJNR Am J Neuroradiol 2007;28:709-13.

18. Matsuki M, Matsuo M, Okada N. Case report: MR findings of a retained surgical sponge. Radiat Med 1998;16:65-7.

19. Gifford RR, Plaut MR, McLeary RD. Retained surgical sponge following laminectomy. JAMA 1973;223:1040. [CrossRef]
20. Mathew JM, Rajshekhar V, Chandy MJ. MRI features of neurosurgical gossypiboma: Report of two cases. Neuroradiology 1996;38:468-9. [CrossRef]

21. Hakan T, Aydoseli A, Demir K, Aker F. Clinical, pathological, and radiological features of paraspinal textiloma:Report of two cases and review of the literature. Neurol Neurochir Pol 2009;43: 475-8.

22. Hyslop JW, Maull KI. Natural history of the retained surgical sponge. South Med J 1982;75:657-60. [CrossRef]

23. Alander DH, Stauffer ES. Gelfoam-induced acute quadriparesis after cervical decompression and fusion. Spine (Phila Pa 1976) 1995;20:970-1. [CrossRef]

24. Chater-Cure G, Fonnegra-Caballero A, Baldion-Elorza AM, JimenezHakim E. Gossypiboma in neurosurgery. Case report and literature review. Neurocirugia (Astur) 2009;20:44-9. [CrossRef]

25. Naama O, Quamous O, Elasri CA, Boulahroud O, Belfkih H, Akhaddar $A$, et al. Textiloma: An uncommon complication of posterior lumbar surgery. J Neuroradiol 2010;37:131-4. [CrossRef]

26. Aydogan M, Mirzanli C, Ganiyusufoglu K, Tezer M, Ozturk I. A 13-year-old textiloma (gossypiboma) after discectomy for lumbar disc herniation: A case report and review of the literature. Spine J 2007;7:618-21. [CrossRef]

27. Yamato $M$, Ido $K$, Izutsu $M$, Narimatsu $Y$, Hiramatsu K. CT and ultrasound findings of surgically retained sponges and towels. J Comput Assist Tomogr 1987;11:1003-6. [CrossRef]

28. Kopka L, Fischer U, Gross AJ, Funke M, Oestmann JW, Grabbe E. CT of retained surgical sponges (textilomas):Pitfalls in detection and evaluation. J Comput Assist Tomogr 1996;20:919-23. [CrossRef]

29. Sakai $T$, Koh $H$, Matsuki A. A case of the foreign body due to "coring". Masui 1996;45:1533-35.

30. Taylor FH, Zollinger RW, Edgerton TA, Harr CD, Shenoy VB. Intrapulmonary foreign body:Sponge retained for 43 years. J Thorac Imaging 1994;9:56-9. [CrossRef]

31. Topal U, Sahin N, Gokalp G, Gebitekin C. Intrathoracic textilomas:Radiologic findings (case report). Tani Girisim Radyol 2004;10:280-3.

32. Rajput A, Loud PA, Gibbs JF, Kraybill WG. Diagnostic challenges in patients with tumors:Case 1. Gossypiboma (foreign body) manifesting 30 years after laparotomy. J Clin Oncol 2003;21:3700-1. [CrossRef]

33. Farina LA, Villavicencio $H$, Chechile G. Preoperatively recognized chronically retained pararenal gauzoma. Int Urol Nephrol 1995;27:33-5. [CrossRef]

34. Van Goethem JW, Parizel PM, Perdieus D, Hermans P, de Moor J. MR and CT imaging of paraspinal textiloma (gossypiboma). J Comput Assist Tomogr 1991;15:1000-3. [CrossRef]

35. Revesz G, Siddiqi TS, Buchheit WA, Bonitatibus M. Detection of retained surgical sponges. Radiology 1983;149:411-3. 